\title{
Modifications of echogenicity of the testis during acute torsion may be a predictive factor of organ damage?
}

\author{
Giuseppe Benedetto, Filippo Nigro, Emiliano Bratti, Andrea Tasca \\ Department of Urology, San Bortolo Hospital, Vicenza, Italy
}

\begin{abstract}
Summary In the setting of symptoms of testicular torsion the absence of diastolic flow or color flow on Doppler ultrasound has traditionally prompted emergent scrotal exploration. This practice emanates from the difficulty on ultrasound of distinguishing salvageable testes from those that are not salvageable. We evaluated the changes of echogenicity in the course of testicular torsion of the testis to identify characteristics predictive of irreversible organ damage.
\end{abstract}

KEY WORDS: Testicular torsion; Echogenicity of testicular torsion.

Submitted 3 October 2014; Accepted 31 October 2014

\section{INTRODUCTION AND AIMS}

During the acute torsion of the testis, in addition to clinical signs and symptoms, the scrotal Doppler ultrasound can be of support in evaluating the absence of testicular flow. We evaluated the changes of echogenicity in the course of testicular torsion of the testis to identify characteristics predictive of irreversible organ damage. flow in the testis wrong. Six boys underwent orchiectomy for testicular necrosis and histological examination documented hemorrhagic necrosis of the testis consistent with testicular torsion.

The ultrasound pattern of these patients documented in all the presence of a dishomogeneous and heterogeneous echotexture of the testis.

In the other eight patients an hypoechoic and isoechoic homogeneous testicular framework was documented, compatible with the integrity of the testis as assessed at scrotal exploration

The average time between the onset of symptoms and the scrotal exploration was 9 hours (range 6-18) in patients in whom the testis was preserved, and 15 hours (range 9-21) in patients undergoing then to orchiectomy. There were no intra- and postoperative complications in patients undergoing orchiectomy

\section{Discussion}

In our series the heterogeneously hypoechoic testicular parenchyma showed an irreversible organ damage that required removal of the organ.

\section{Material and Methods}

We retrospectively analyzed, the scrotal ultrasound of patients undergoing scrotal exploration for testicular torsion in the last year in our department, evaluating the sonographic features and comparing them to the outcome of the scrotal exploration, and in case of orchiectomy to outcome for histology. Was also evaluated the average time between the onset of symptoms and evaluation in the emergency room and the scrotal exploration.

\section{RESULTS}

During the past year, 14 children were evaluated at our department for acute torsion of the testis and underwent scrotal exploration. All underwent preoperative scrotal Doppler ultrasound that documented the absence of
Figure.

Dishomogeneous torsion testis alteration.

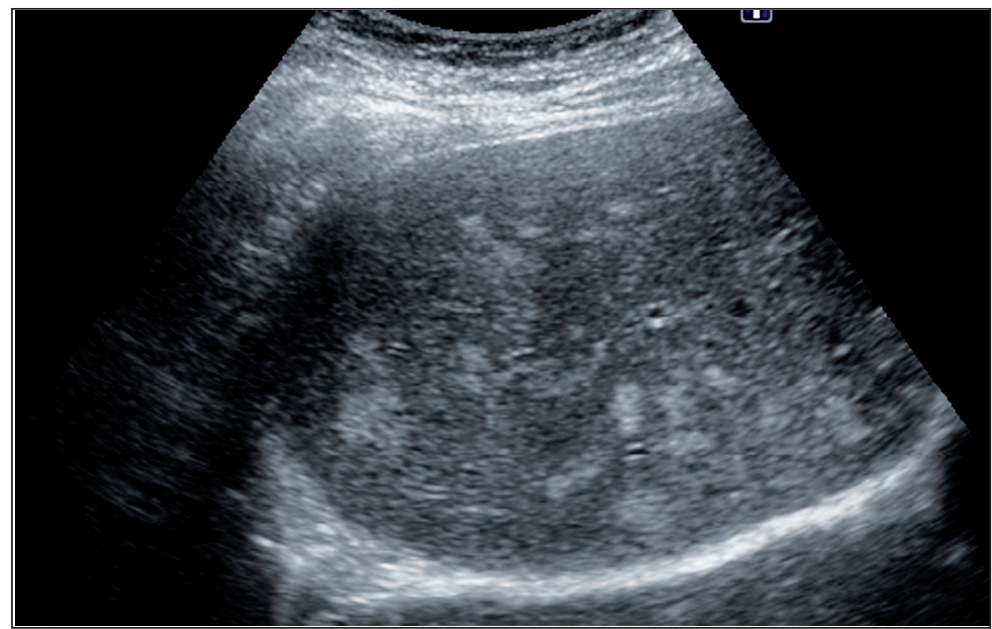


Therefore, taking into account echotexture and obvious signs of torsion scrotal exploration cannot be emergent. On the other hand, an homogeneous echotexture heralds testicular viability and the need to scrotal exploration in emergency.

\section{Conclusion}

We evaluated the changes of echogenicity in the course of testicular torsion of the testis to identify characteristics predictive of irreversible organ damage.
However the smallness of our sample requires confirmation by in-depth studies of larger series.

\section{REFERENCES}

1. Kaye JD, Shapiro EY, Levitt SB, et al. Parenchymal echo texture predicts testicular salvage after torsion: potential impact on the need for emergent exploration.J Urol. 2008; 180 (4 Suppl):1733-6.

2. Nistal M, Paniagua R, Gonzalez-Peramato P, Reyes-Múgica M. Testicular torsion, testicular appendix torsion and other forms of testicular infarction. Pediatr Dev Pathol. 2014.

\section{Correspondence}

Giuseppe Benedetto, MD

g_benedetto@yahoo.it

Filippo Nigro, MD

Filippo.nigro@ulssvicenza.it

Emiliano Bratti, MD

Emiliano.bratti@ulssvicenza.it

Andrea Tasca, MD

Andrea.Tasca@ulssvicenza.it

UOC Urologia, Ospedale San Bortolo,

Via Rodolfi, 37 - Vicenza, Italy 